Open Access

\title{
Association between a vascular endothelial growth factor gene polymorphism (rs2146323) and diabetic retinopathy: a meta-analysis
}

Ying Zeng ${ }^{1{ }^{*}+}$, Fangjie Dai ${ }^{1 \dagger}$, Ke Yang $^{2+}$, Yongqing Tang ${ }^{3}$, Meng Xu ${ }^{1}$ and Yiwu Zhou ${ }^{1}$

\begin{abstract}
Background: Vascular endothelial growth factor (VEGF) is thought to play an important role in the pathogenesis of diabetic retinopathy (DR). Previous studies have associated the VEGF rs2146323 polymorphism with the risk of DR. However, the results of these studies are inconsistent. A meta-analysis was performed to evaluate the association between the VEGF rs2146323 polymorphism and the risk of DR.

Methods: The PubMed, EMBASE, Web of Science and Google Scholar literature databases until March 2015 were searched. The differences in the studies were expressed in the form of an odds ratio (OR) and the corresponding $95 \%$ confidence interval $(\mathrm{Cl})$. Heterogeneity among the studies was tested using the $\mathrm{I}^{2}$ statistic based on the $\mathrm{Q}$ test.

Results: A total of four studies (598 cases and 709 controls) were included in the meta-analysis. A significant association was found involving the rs2146323 polymorphism in the dominant model (CA + AA VS. CC) (OR $=1.38, \mathrm{Cl}=1.10-1.72$, $P=0.005)$ and the co-dominant model (CA VS. CC) (OR=1.37, $\mathrm{Cl}=1.08-1.74, P=0.008)$.
\end{abstract}

Conclusions: Our meta-analysis confirmed the association between the VEGF rs2146323 polymorphism and the risk of DR.

Keywords: Vascular endothelial growth factor, Polymorphism, Meta-analysis, Diabetic retinopathy

\section{Background}

Diabetic retinopathy (DR) is considered one of the most common microvascular complications in diabetes. It leads to blindness among adults aged $20-74$ years and is regarded as the main cause of blindness in people with diabetes [1]. Although the mechanisms of DR remain largely unknown, increasing evidence has implicated both genetics and environmental factors in the pathogenesis of DR [2,3].

VEGF is expressed and secreted from vascular endothelial cells [4], Müller cells [5], astrocytes [6], retinal pigment epithelial cells (RPE) [7], and ganglion cells [8];

\footnotetext{
* Correspondence: zengying@tongji.edu.cn

${ }^{\dagger}$ Equal contributors

'Department of Ophthalmology of the Shanghai Tenth People's Hospital, and Laboratory of Clinical Visual Sciences of Tongji Eye Institute, and Department of Regenerative Medicine, Tongji University School of Medicine, Shanghai, China

Full list of author information is available at the end of the article
}

it exerts its physiological effects by mediating vascular permeability, angiogenesis, endothelial cell growth, cell migration, and apoptosis [9]. Increased levels of VEGF in the blood and the retina are linked to the pathogenesis of DR [10]. Moreover, Anti-VEGF therapy is currently recommended for patients with diabetic macular edema, a very specific subtype of DR [11].

The human VEGF gene is located on chromosome 6p21.3 with 7 introns and 8 exons and shows polymorphism [12]. Many VEGF SNPs have been reported showing association with DR, such as rs699947 [13], rs833061 [14], rs3025039 [15], which have been assessed quantitatively by meta-analyses [16-18]. But we noted that rs2146323 have been reported showing inconsistent association with DR [19-24]. Therefore, we conducted this meta-analysis.

A meta-analysis is a statistical procedure of pooling the data from individual studies, increasing the effective 
sample size, and producing a single estimate of an effect [25]. The aim of our study was to evaluate the association between the VEGF rs2146323 polymorphism and DR by performing a meta-analysis.

\section{Methods}

Literature search and inclusion criteria

All the literature in PubMed, EMBASE, Web of Science, Google Scholar literature databases was searched. The search included only English language publications before the deadline of the March 1st, 2015. To search all of the literature related to the rs2146323 polymorphism, we used the following search strategies: (vascular endothelial growth factor or VEGF or VEGFA or "vascular endothelial growth factor A/genetics"[mesh]) and (diabetic retinopathy or diabetes retinopathy or DR or "diabetic retinopathy/ genetics'[mesh] or "macular edema/genetics" [mesh]). We chose the literature that involved the polymorphism based on the title and abstract of the articles and even the full text when necessary. The meta-analysis was performed for cases with any form of DR compared with diabetic without retinopathy (DWR). After removal of the duplicates, we used the following inclusion criteria to filter the articles: (1) the study was a case-control study; (2) definitive methods were applied to the diagnosis of diabetic retinopathy, including the Early Treatment of Diabetic Retinopathy Study (ETDRS) and the guidelines of the Expert Committee Report of the American Diabetes Association (DR includes proliferative diabetic retinopathy (PDR) and non-proliferative diabetic retinopathy (NPDR)); (3) the VEGF rs2146323 polymorphism was evaluated; (4) the sample size was sufficient for the calculation of the odds ratio (OR) with $95 \%$ confidence interval (CI); and (5) the control group followed Hardy-Weinberg equilibrium (HWE; a $X^{2}$ value of Pearson's chi-square test $>3.84 \quad(\mathrm{df}=1)$ indicates deviation from HWE $)$. The most recent article will be used to extract data if the authors published more than one article with the same study data.

\section{Data extraction and quality assessment}

The data were independently extracted by two reviewers and both of the reviewers' results were submitted to a third reviewer who verified the results. If there were inconsistencies, the three reviewers discussed the disagreements to resolve the differences. The following items were extracted: (1) the name of the first author; (2) the year of publication; (3) the origin country; (4) the racial descent of the study population; (5) the sample size of the cases and controls; (6) duration of diabetes; (7) gender ration (male, \%); (8) HbA1c level; (9) the genotype frequency; (10) the genotyping methods; and
(11) the HWE (for the studies in which there was no HWE assessment, we calculated this parameter) [26]. The Newcastle-Ottawa Scale (NOS) tools, which were recommended by Cochrane, were used to evaluate the quality of the eligible studies, like a previous study [27].

\section{Statistical analysis}

The six genetics models were used for analyses: dominant model: $\mathrm{CA}+\mathrm{AA}$ vs. $\mathrm{CC}$; allele model: A vs. C; recessive model: AA vs. $\mathrm{CA}+\mathrm{CC}$; co-dominant model: $\mathrm{CA}$ vs. $\mathrm{CC}$; co-dominant model means AA vs. CC; overdominant model means $\mathrm{CA}$ vs. $\mathrm{CC}+\mathrm{AA}$; additive model: $\mathrm{CC}$ vs. AA [25]. The differences in the studies were expressed in the form of the odds ratio (OR) and the corresponding $95 \%$ confidence interval (CI). The pooled OR was evaluated in 6 genetic models. The pooled OR was determined using a $\mathrm{Z}$ test $(\mathrm{PZ}<0.05$ was considered statistically significant). Heterogeneity among studies was tested by the $\mathrm{I}^{2}$ statistic based on Q test. Studies with $\mathrm{I}^{2}<50 \%$ or $P>0.10$ were considered to be of low heterogeneity, and the fixed effects model was used to calculated the pooled OR, otherwise, random effects model was used to pool OR. STATA software (version 12.0; STATA Corporation, College Station, TX, USA) was used for the analyses. Two-sided $P<0.05$ was considered statistically significant.

\section{Results}

\section{Characteristics of the studies}

A total of 2724 articles were retrieved in the initial search. Of these, 207 articles were written in a nonEnglish language, 2479 articles were irrelevant regarding the $V E G F$ polymorphism in DR, and 32 articles were irrelevant regarding the VEGF rs 2146323 polymorphism were excluded based on reading the titles or abstracts. In addition, 2 articles were excluded because one was not a case-control study [24] and one was a study previously reported by same author concerning the same population [23]. The flow chart describing the inclusion and exclusion of the studies is shown in Fig. 1, and the characteristics of the included studies are listed in Table 1. The characteristics and the quality assessment of eligible studies are listed in Table 1. Generally, the quality of included studies was moderate. The major design deficiencies of eligible studies were as follows: 1) the authors did not report whether the subjects were consecutively enrolled; 2) confounding factors were not well controlled; and 3) non-response rates were not reported.

\section{Pooled effects analyses}

A total of 598 diabetes with retinopathy (DR) cases and 709 diabetes without retinopathy (DWR) controls were 
2724 reconds retrieved from PubMed, EMBASE, Web of

Science, Google Scholar literature databases and VIP

207 records were excluded:

other languages

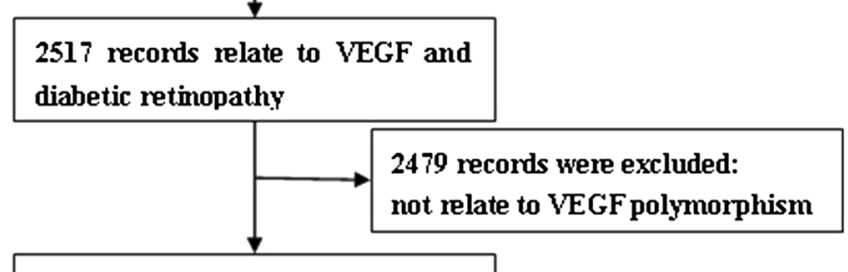

38 records relevant to VEGF

polymorphism

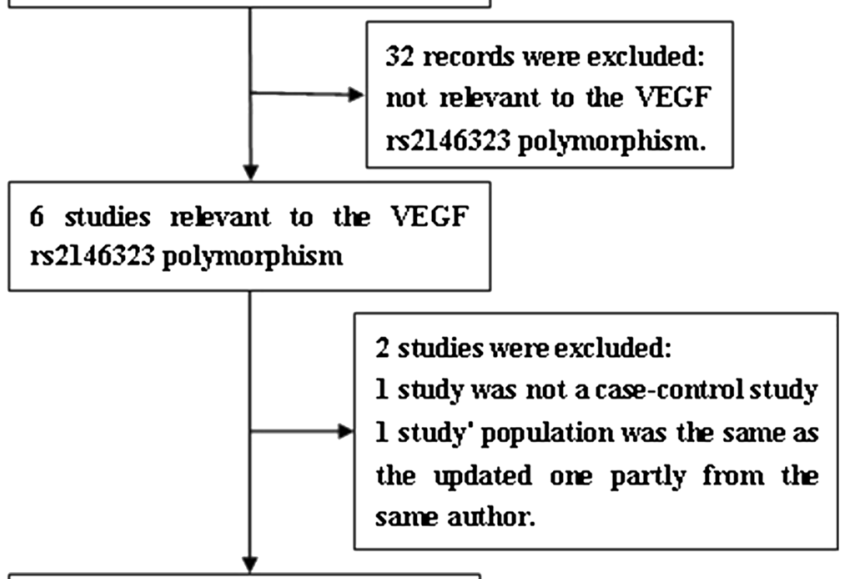

4 studies finally were included in

the meta-analysis.

Fig. 1 Flow chart of the inclusion and exclusion of the studies

identified (Table 2), and 6 genetic models were performed for analyzing the association between the rs2146323 polymorphism and DR. Our results showed a significant association between the rs2146323 polymorphism and DR in the dominant model (CA + AA VS CC $)(\mathrm{OR}=1.38, \mathrm{CI}=1.10-1.72, \mathrm{PZ}=0.005, \mathrm{PH}=0.741)$ (Fig. 2) and in the co-dominant model (CA VS CC) $(\mathrm{OR}=1.37, \quad \mathrm{CI}=1.08-1.74, \quad \mathrm{PZ}=0.008, \quad \mathrm{PH}=0.529)$ (Fig. 3). No significant heterogeneity was found between the two models. In the genetic models with significant association, the Caucasian subgroups were consistent with the overall patient population (dominant model, OR $=1.37, \mathrm{CI}=1.03-1.81, \mathrm{PZ}=0.031, \mathrm{PH}=0.538$; co-dominant model, $\mathrm{OR}=1.52, \mathrm{CI}=1.13-2.04, \mathrm{PZ}=0.006, \mathrm{PH}=$ $0.601)$. However, no significant association was found in the Chinese subgroup (dominant model, OR = 1.40, PZ $=0.070$; co-dominant model CA VS CC, OR $=1.15, \mathrm{PZ}=0.470)($ Table 2$)$.

Table 1 Characteristics and quality assessment of the included studies

\begin{tabular}{|c|c|c|c|c|c|c|c|c|c|c|}
\hline Author & Year & Ethnicity & Country & $N$ & Diabetes & $\begin{array}{l}\text { Duration of diabetes } \\
\text { (DR/DWR), years }\end{array}$ & $\begin{array}{l}\text { Male } \\
\text { (DR/DWR), \% }\end{array}$ & $\begin{array}{l}\mathrm{HbA1c} \\
\text { (DR/DWR), \% }\end{array}$ & $\begin{array}{l}\text { Genotype } \\
\text { typing }\end{array}$ & NOS \\
\hline Yang XF [22] & 2014 & Asian & China & 490 & Type 2 & $15 \pm 5 / 13 \pm 7$ & $0.45 / 0.39$ & $7.8 \pm 1.7 / 7.0 \pm 1.4$ & PCR-RFLP & 5 \\
\hline Kangas-Kontio T [21] & 2009 & Caucasian & Finland & 224 & Type 1/2 & $24 \pm 10 / 25 \pm 7$ & $0.60 / 0.51$ & Not reported & RT-PCR/Taqman & 6 \\
\hline \multirow[t]{2}{*}{ Abhary S [19] } & 2009 & Caucasian & Australia & 487 & Type 1 & $31 \pm 13 / 15 \pm 9$ & $0.39 / 0.48$ & $8.8 \pm 2.3 / 7.6 \pm 2.5$ & Mass spectrometer & 5 \\
\hline & & & & & Type 2 & $18 \pm 9 / 13 \pm 9$ & $0.56 / 0.65$ & $7.5 \pm 3.4 / 6.6 \pm 2.9$ & & \\
\hline Churchil AJ [20] & 2008 & Caucasian & UK & 106 & Type 1/2 & $23 / 25$ & $0.60 / 0.52$ & Not reported & PCR-RFLP & 5 \\
\hline
\end{tabular}


Table 2 Genotype frequency of VEGF rs2146323 polymorphism

\begin{tabular}{|c|c|c|c|c|c|c|c|c|}
\hline \multirow[t]{2}{*}{ Author } & \multirow[t]{2}{*}{ DR/DWR } & \multicolumn{3}{|c|}{ DWR } & \multicolumn{3}{|l|}{ DR } & \multirow[t]{2}{*}{ HWE $(x 2)$} \\
\hline & & CC & CA & AA & $\mathrm{CC}$ & CA & AA & \\
\hline Yang XF [22] & $214 / 276$ & 112 & 72 & 30 & 167 & 93 & 16 & 0.4 \\
\hline Kangas-Kontio T [21] & $127 / 97$ & 47 & 61 & 19 & 40 & 44 & 13 & 0.03 \\
\hline Abhary S [19] & $212 / 275$ & 77 & 113 & 22 & 129 & 113 & 33 & 1.13 \\
\hline Churchil AJ [20] & $45 / 61$ & 19 & 26 & 0 & 26 & 22 & 13 & 3.64 \\
\hline
\end{tabular}

\section{Risk evaluation of publication bias and sensitive analyses}

We presented a basic symmetry with disperse and uniform points in Begg' funnel plot. Further statistical analysis show that there were no publication bias in the inclusive studies (dominant model: Begg' test $P=0.308$, Egger's test $P=0.083$; allele model: Begg' test $P=0.308$, Egger's test $P=0.145$; recessive model: Begg' test $P=0.734$, Egger's test $P=0.387$; co-dominant model CA VS CC: Begg' test $P=1.000$, Egger's test $P=0.968$; codominant model AA VS CC: Begg' test $P=0.734$, Egger's test $P=0.272$; over-dominant model: Begg' test $P=0.734$, Egger's test $P=0.595$; additive model: Begg' test $P=0.734$, Egger's test $P=0.272$ ). We conducted the sensitivity analysis, and results show that the pooled OR was close to the total pooled OR and was within the total $95 \% \mathrm{CI}$, which indicated that the results of sensitive analyses for these studies were reliable (Figs. 4 and 5).

\section{Discussion}

The present meta-analysis confirmed the association between the VEGF rs2146323 polymorphism and DR. Churchil et al. [20] first reported that the $+5092 \mathrm{C} / \mathrm{A}$ (rs2146323) polymorphism was significantly associated with proliferative diabetic retinopathy (PDR) in a Caucasian population with type 1 or 2 diabetes, although the sample size for analyzing this polymorphism was relatively small. However, subsequent studies showed inconsistent results. Abhary et al. [19] investigated whether the rs2146323 polymorphism was significantly associated with blinding DR in type 1 but not in type 2 diabetic patients. Kangas-kontio et al. [21] reported no association between rs2146323 and DR. Yang XF et al. [22] first reported a signification association in Chinese type 2 diabetic patients. Considering that the data are not sufficient, we could not exclude the correlation between the type of diabetes and the results. The results from Caucasian populations were consistent with the overall results. However, because only one study in the Chinese population and three studies in the Caucasian population were investigated,

Table 3 Pooled ORs and $95 \%$ Cls of the association between the VEGF rs2146323 polymorphism and DR in six models

\begin{tabular}{|c|c|c|c|c|c|c|c|c|}
\hline \multirow[t]{2}{*}{ Model } & \multirow[t]{2}{*}{ Contrasts } & \multirow[t]{2}{*}{ Number of study } & \multirow[t]{2}{*}{ Pooled method } & \multirow[t]{2}{*}{ OR $(95 \% \mathrm{Cl})$} & \multirow[t]{2}{*}{ Z } & \multirow[t]{2}{*}{$\mathrm{Pz}$} & \multicolumn{2}{|c|}{ Heterogeneity } \\
\hline & & & & & & & $1^{2}$ & P \\
\hline \multirow[t]{3}{*}{ Dominant CA + AA vs. CC } & Chinese & 1 & Fixed-effect & $1.40(0.97-2.00)$ & 1.81 & 0.070 & & \\
\hline & Caucasian & 3 & & $1.37(1.03-1.81)$ & 2.16 & 0.031 & $0.0 \%$ & 0.538 \\
\hline & Overall & 4 & & $1.38(1.10-1.72)$ & 2.82 & 0.005 & $0.0 \%$ & 0.741 \\
\hline \multirow[t]{3}{*}{ Allele A vs. C } & Chinese & 1 & Random-effect & $1.52(1.14-2.03)$ & 2.88 & 0.004 & & \\
\hline & Caucasian & 3 & & $1.03(0.75-1.43)$ & 0.19 & 0.847 & $52.1 \%$ & 0.124 \\
\hline & Overall & 4 & & $1.16(0.88-1.53)$ & 1.02 & 0.306 & $59.9 \%$ & 0.058 \\
\hline \multirow[t]{3}{*}{ Recessive AA vs. CA + CC } & Chinese & 1 & Random-effect & $2.65(1.40-5.00)$ & 3.01 & 0.003 & & \\
\hline & Caucasian & 3 & & $0.73(0.29-1.85)$ & 0.67 & 0.504 & $63.9 \%$ & 0.063 \\
\hline & Overall & 4 & & $1.04(0.43-2.53)$ & 0.09 & 0.928 & $77.5 \%$ & 0.004 \\
\hline \multirow[t]{3}{*}{ Co-dominant CA vs. CC } & Chinese & 1 & Fixed-effect & $1.15(0.78-1.71)$ & 0.72 & 0.470 & & \\
\hline & Caucasian & 3 & & $1.52(1.13-2.04)$ & 2.75 & 0.006 & $0.0 \%$ & 0.601 \\
\hline & Overall & 4 & & $1.37(1.08-1.74)$ & 2.63 & 0.008 & $0.0 \%$ & 0.529 \\
\hline \multirow[t]{3}{*}{ Co-dominant AA vs. CC } & Chinese & 1 & Random-effect & $2.80(1.46-5.37)$ & 3.09 & 0.002 & & \\
\hline & Caucasian & 3 & & $0.89(0.35-2.24)$ & 0.25 & 0.801 & $59.0 \%$ & 0.087 \\
\hline & Overall & 4 & & $1.26(0.56-2.84)$ & 0.55 & 0.585 & $70.8 \%$ & 0.016 \\
\hline \multirow[t]{3}{*}{ Over-dominant CA vs. CC + AA } & Chinese & 1 & Random-effect & $1.00(0.68-1.46)$ & 0.01 & 0.991 & & \\
\hline & Caucasian & 3 & & $1.55(1.09-2.21)$ & 2.41 & 0.016 & $29.1 \%$ & 0.244 \\
\hline & Overall & 4 & & $1.36(0.96-1.91)$ & 1.74 & 0.081 & $51.2 \%$ & 0.105 \\
\hline \multirow[t]{3}{*}{ Additive CC vs. AA } & Chinese & 1 & Random-effect & $0.36(0.19-0.69)$ & 3.09 & 0.002 & & \\
\hline & Caucasian & 3 & & $1.10(0.46-2.66)$ & 0.22 & 0.828 & $55.2 \%$ & 0.107 \\
\hline & Overall & 4 & & $0.79(0.36-1.76)$ & 0.57 & 0.567 & $69.8 \%$ & 0.019 \\
\hline
\end{tabular}




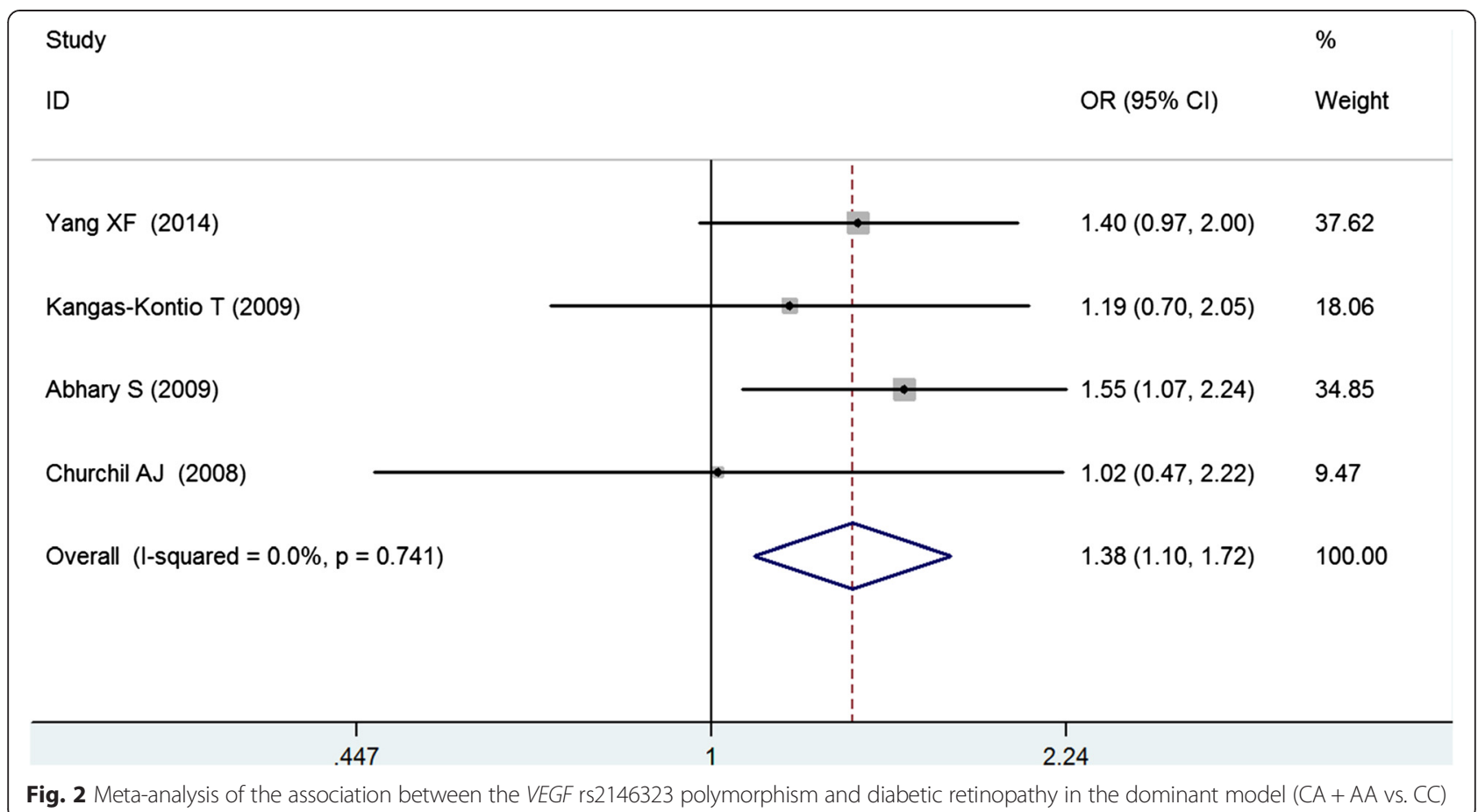

further studies on this polymorphism might involve additional data that includes the population, type of DR, and more complicated genetic or environmental background.

To date, the mechanism of the involvement of VEGF in DR development remains unclear. VEGF plays a crucial role in DR by increasing the vascular permeability and neovascularization [4]. Beyond the present study, $V E G F$ polymorphisms are significantly associated with the risk of DR [28-30]. The significant VEGF gene polymorphism promotes $V E G F$ gene expression and increases the levels of VEGF in the serum [31] and the vitreous of the eyes of diabetic patients [32]. However, we could not analyze the rs2146323 and VEGF levels in

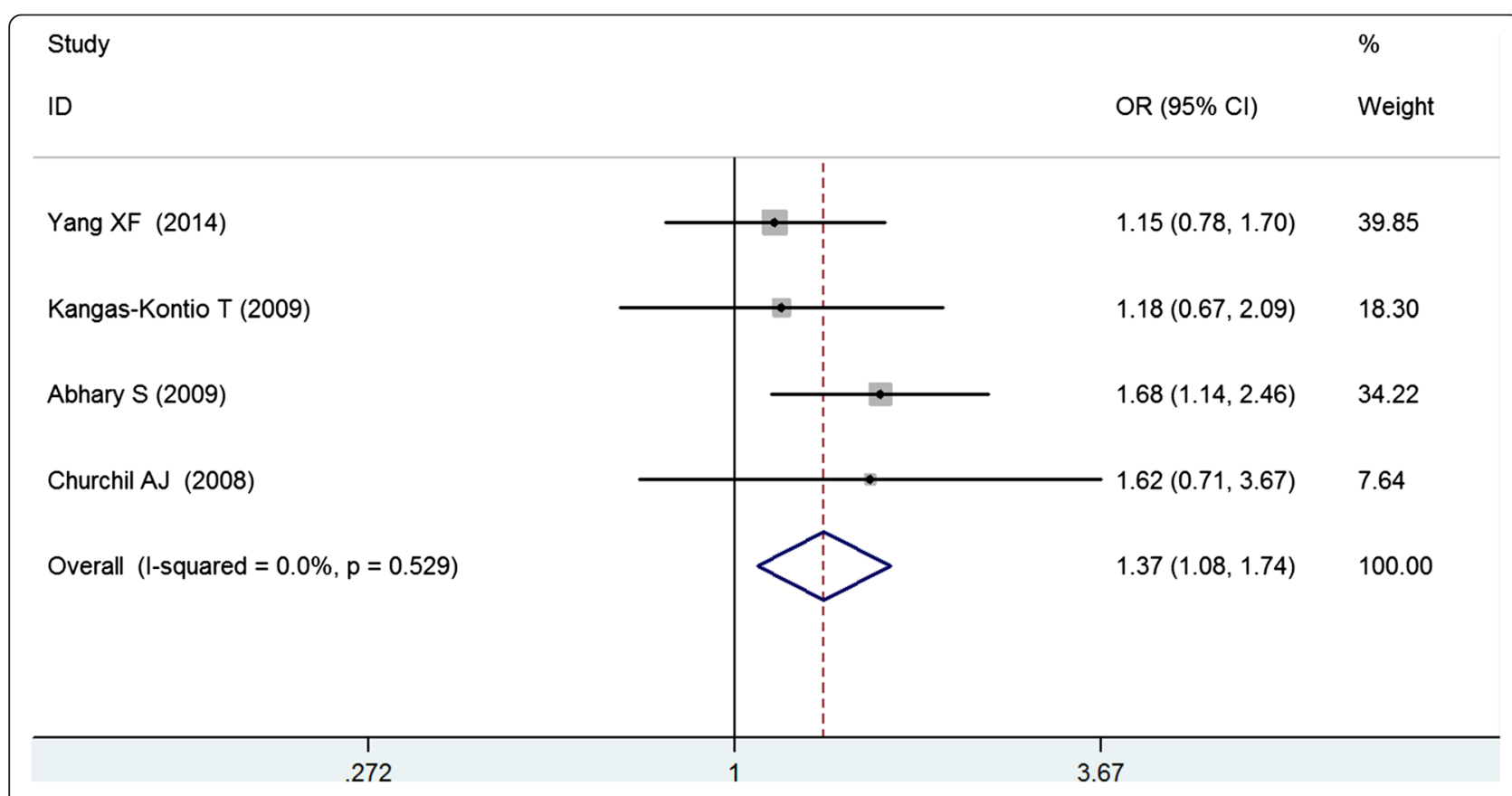

Fig. 3 Meta-analysis of the association between the VEGF rs2146323 polymorphism and diabetic retinopathy in the co-dominant model (CA vs. CC) 


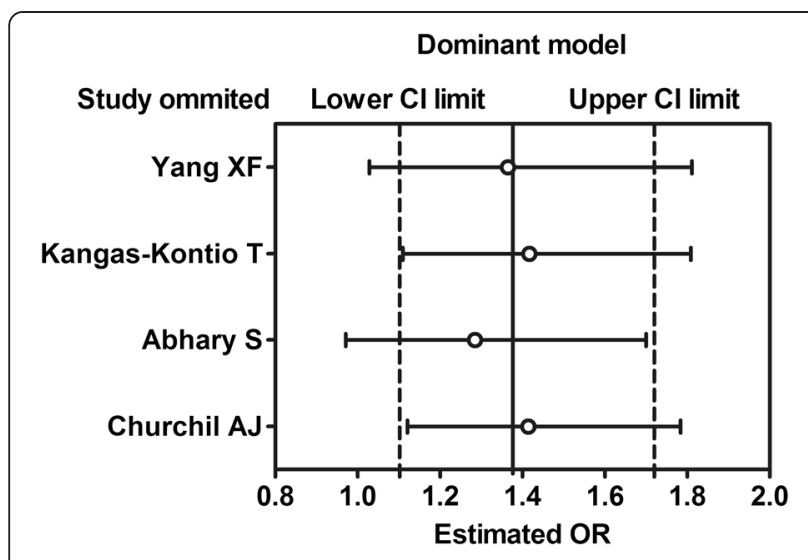

Fig. 4 Sensitivity analysis in the dominant model (CA + AA vs. CC)

both blood and the vitreous of diabetic eyes because of insufficient direct data on VEGF expression levels. VEGF $+5092 \mathrm{C} / \mathrm{A}$ is located in 111-bp $5^{\prime}$ of exon 3, where it is distant from the predicted transcription factor binding sites and is not predicted to be involved in exon splicing alterations [20]. Thus, this makes it more effective for unveiling the mechanism of this polymorphism on VEGF expression and function.

There are several limitations of this meta-analysis. First, the sample size is relatively small because only four studies were included in the meta-analysis. Second, the effects of the type of diabetes on the association between the polymorphism and DR were not addressed because the primary studies did not provide the relevant data. Third, in an attempt to overcome the confounding results of undetectable population stratification, we limited the case and control groups to include only Caucasian ethnicity. We found that the Caucasian subgroups were consistent with the overall patient population. However, there are several uncontrolled confounding factors (age, sex, and duration of diabetes, blood glucose level, medication use, and other complications). Fourth, the present

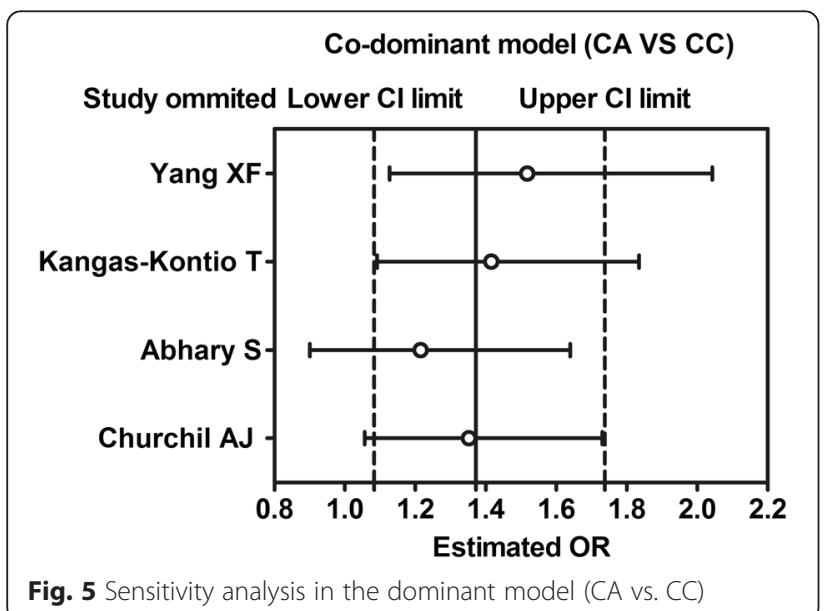

studies did not provide the physical and biochemical examination results, which are useful for interpreting the mechanism of the polymorphism in DR. Finally, although DR cases were classified by fundus photographs or OCT, level of DR has been not presented, which may be the source of heterogeneity.

\section{Conclusions}

In conclusion, our meta-analysis results indicated that there was a significant association between the VEGF rs2146323 polymorphism and the risk of DR. Since most of these polymorphisms are in strong linkage disequilibrium, genome-wide association study (GWAS) can provide more genome-wide genetic association with DR.

\section{Competing interests}

Yongqing Tang is an employee of Great China Region of Novartis who was only responsible for idea on study design. Other authors of this manuscript declare no conflict of interest and have no financial relationship with organizations.

\section{Authors' contributions}

Conceived and designed the study: Ying Zeng, Ke Yang, and Yongqing Tang; Acquisition of data: Fangjie Dai, Meng Xu, and Yiwu Zhou; Analysis and interpretation of data: Ying Zeng and Ke Yang; Drafting the manuscript: Ying Zeng and Fangjie Dai; Revising the manuscript critically for important intellectual content: Ying Zeng, Ke Yang. All authors read and approved the final manuscript.

\section{Author details}

${ }^{1}$ Department of Ophthalmology of the Shanghai Tenth People's Hospital, and Laboratory of Clinical Visual Sciences of Tongji Eye Institute, and Department of Regenerative Medicine, Tongji University School of Medicine, Shanghai, China. ${ }^{2}$ Institute of Cardiovascular Disease, Ruijin Hospital, Shanghai Jiaotong University School of Medicine, Shanghai, China. ${ }^{3}$ Department of Development, Great China Region of Novartis, Shanghai, China.

Received: 16 August 2015 Accepted: 4 November 2015

Published online: 09 November 2015

\section{References}

1. Cheung N, Mitchell P, Wong TY. Diabetic retinopathy. Lancet. 2010;376:124-36.

2. Hosseini SM, Boright AP, Sun L, Canty AJ, Bull SB, Klein BE, et al. The association of previously reported polymorphisms for microvascular complications in a meta-analysis of diabetic retinopathy. Hum Genet. 2015;134:247-57.

3. Sobrin L, Green T, Sim X, Jensen RA, Tai ES, Tay WT, et al. Candidate gene association study for diabetic retinopathy in persons with type 2 diabetes: the Candidate gene Association Resource (CARe). Invest Ophthalmol Vis Sci. 2011;52:7593-602.

4. Ferrara N, Davis-Smyth T. The biology of vascular endothelial growth factor. Endocr Rev. 1997;18:4-25.

5. Pierce EA, Avery RL, Foley ED, Aiello LP, Smith LE. Vascular endothelial growth factor/vascular permeability factor expression in a mouse model of retinal neovascularization. Proc Natl Acad Sci USA. 1995;92:905-09.

6. Stone J, Itin A, Alon T, Pe'er J, Gnessin H, Chan-Ling T, et al. Development of retinal vasculature is mediated by hypoxia-induced vascular endothelial growth factor (VEGF) expression by neuroglia. J Neurosci. 1995;15:4738-47.

7. Miller JW, Adamis AP, Aiello LP. Vascular endothelial growth factor in ocular neovascularization and proliferative diabetic retinopathy. Diabetes Metab Rev. 1997;13:37-50. 
8. Stone J, Chan-Ling T, Pe'er J, Itin A, Gnessin H, Keshet E. Roles of vascular endothelial growth factor and astrocyte degeneration in the genesis of retinopathy of prematurity. Invest Ophthalmol Vis Sci. 1996;37:290-9.

9. Shibuya M. Vascular endothelial growth factor and its receptor system: physiological functions in angiogenesis and pathological roles in various diseases. J Biochem. 2013;153:13-9.

10. Kusari J, Zhou SX, Padillo E, Clarke KG, Gil DW. Inhibition of vitreoretinal VEGF elevation and blood-retinal barrier breakdown in streptozotocin-induced diabetic rats by brimonidine. Invest Ophthalmol Vis Sci. 2010:51:1044-51.

11. Boyd SR, Advani A, Altomare F, Stockl F. Retinopathy. Can J Diabetes. 2013;Suppl 1:S137-141.

12. Arcondéguy $T$, Lacazette $E$, Millevoi $S$, Prats $H$, Touriol C. VEGF-A mRNA processing, stability and translation: a paradigm for intricate regulation of gene expression at the post-transcriptional level. Nucleic Acids Res. 2013;41:7997-8010.

13. Chun MY, Hwang HS, Cho HY, Chun HJ, Woo JT, Lee KW, et al. Association of vascular endothelial growth factor polymorphisms with nonproliferative and proliferative diabetic retinopathy. J Clin Endocrinol Metab. 2010;95:3547-51.

14. Awata $T$, Inoue $K$, Kurihara $S$, Ohkubo $T$, Watanabe $M$, Inukai $K$, et al. A common polymorphism in the $5^{\prime}$-untranslated region of the VEGF gene is associated with diabetic retinopathy in type 2 diabetes. Diabetes. 2002;51:1635-9.

15. Uthra S, Raman R, Mukesh BN, Rajkumar SA, Padmaja KR, Paul PG, et al. Association of VEGF gene polymorphisms with diabetic retinopathy in a south Indian cohort. Ophthalmic Genet. 2008;29:11-5.

16. Lu Y, Ge Y, Shi Y, Yin J, Huang Z. Two polymorphisms (rs699947, rs2010963) in the VEGFA gene and diabetic retinopathy: an updated meta-analysis. BMC Ophthalmol. 2013;13:56.

17. Gong JY, Sun YH. Association of VEGF gene polymorphisms with diabetic retinopathy: a meta-analysis. PLoS One. 2013;8:e84069.

18. Han L, Zhang L, Xing W, Zhuo R, Lin X, Hao Y, et al. The associations between VEGF gene polymorphisms and diabetic retinopathy susceptibility: a meta-analysis of 11 case-control studies. J Diabetes Res. 2014:2014:805801.

19. Abhary S, Burdon KP, Gupta A, Lake S, Selva D, Petrovsky N, et al. Common sequence variation in the VEGFA gene predicts risk of diabetic retinopathy. Invest Ophthalmol Vis Sci. 2009;50:5552-8.

20. Churchill AJ, Carter JG, Ramsden C, Turner SJ, Yeung A, Brenchley PE, et al. VEGF polymorphisms are associated with severity of diabetic retinopathy. Invest Ophthalmol Vis Sci. 2008;49:3611-6.

21. Kangas-Kontio T, Vavuli S, Kakko SJ, Penna J, Savolainen ER, Savolainen MJ, et al. Polymorphism of the manganese superoxide dismutase gene but not of vascular endothelial growth factor gene is a risk factor for diabetic retinopathy. Br J Ophthalmol. 2009;93:1401-6.

22. Yang X, Deng $Y$, Gu H, Ren X, Li N, Lim A, et al. Candidate gene association study for diabetic retinopathy in Chinese patients with type 2 diabetes. Mol Vis. 2014;20:200-14.

23. Yang $X$, Deng $Y$, Gu H, Lim A, Altankhuyag A, Jia W, et al. Polymorphisms in the vascular endothelial growth factor gene and the risk of diabetic retinopathy in Chinese patients with type 2 diabetes. Mol Vis. 2011;17:3088-96.

24. Al-Kateb $H$, Mirea L, Xie X, Sun L, Liu M, Chen $H$, et al. Multiple variants in vascular endothelial growth factor (VEGFA) are risk factors for time to severe retinopathy in type 1 diabetes: the DCCT/EDIC genetics study. Diabetes. 2007;56:2161-8.

25. Lee YH. Meta-Analysis of Genetic Association Studies. Ann Lab Med. 2015;35:283-7.

26. Rodriguez S, Gaunt TR, Day IN. Hardy-Weinberg equilibrium testing of biological ascertainment for Mendelian randomization studies. Am J Epidemiol. 2009;169:505-14.

27. Li D, Peng XY, Sun HY. Association of TCF4 polymorphisms and fuchs' endothelial dystrophy: a meta-analysis. BMC Ophthalmol. 2015;15:61.

28. Feghhi M, Nikzamir A, Esteghamati A, Mahmoudi T, Yekaninejad MS. Relationship of vascular endothelial growth factor (VEGF) +405 G/C polymorphism and proliferative retinopathy in patients with type 2 diabetes. Transl Res. 2011;158:85-91.

29. Kim HW, Ko GJ, Kang YS, Lee MH, Song HK, Kim HK, et al. Role of the VEGF $936 \mathrm{C} / \mathrm{T}$ polymorphism in diabetic microvascular complications in type 2 diabetic patients. Nephrology (Carlton). 2009;14:681-8.
30. Errera Fl, Canani LH, Silva ME, Yeh E, Takahashi W, Santos KG, et al. Functional vascular endothelial growth factor -634G > C SNP is associated with proliferative diabetic retinopathy: a case-control study in a Brazilian population of European ancestry. Diabetes Care. 2007;30:275-9.

31. Choudhuri S, Chowdhury IH, Das S, Dutta D, Saha A, Sarkar R, et al. Role of NF-KB activation and VEGF gene polymorphisms in VEGF upregulation in non-proliferative and proliferative diabetic retinopathy. Mol Cell Biochem. 2015:405:265-279.

32. Nakamura S, Iwasaki N, Funatsu H, Kitano S, Iwamoto Y. Impact of variants in the VEGF gene on progression of proliferative diabetic retinopathy. Graefes Arch Clin Exp Ophthalmol. 2009;247:21-6.

\section{Submit your next manuscript to BioMed Central and take full advantage of:}

- Convenient online submission

- Thorough peer review

- No space constraints or color figure charges

- Immediate publication on acceptance

- Inclusion in PubMed, CAS, Scopus and Google Scholar

- Research which is freely available for redistribution

Submit your manuscript at www.biomedcentral.com/submit 